\title{
Case Report Of Cryoneurolysis For The Treatment Of Refractory Intercostobrachial Neuralgia With Postherpetic Neuralgia
}

This article was published in the following Dove Press journal: Local and Regional Anesthesia

\section{Garret Weber (DD \\ Kenneth Saad \\ Motaz Awad \\ Tiffany $\mathrm{H}$ Wong}

Department of Anesthesiology, New York Medical College, Valhalla, NY, USA

\begin{abstract}
Postherpetic neuralgia is a common and potentially debilitating neuropathic pain condition. Current pharmacologic therapy can be inadequate and intolerable for patients. We present a case of a gentleman with refractory postherpetic neuralgia in the intercostobrachial nerve distribution that was successfully treated with cryoneurolysis/cryoanalgesia therapy.
\end{abstract}

Keywords: cryoneurolysis, cryoablation, postherpetic neuralgia, intercostobrachial neuralgia, neuropathic pain

\section{Introduction}

Postherpetic neuralgia (PHN) is one of the most common painful chronic neuropathic pain conditions and it occurs following an acute herpes zoster infection ${ }^{1}$ herpes zoster, and PHN generally presents along a unilateral thoracic dermatome, with $20 \%$ involving multiple adjacent dermatomes. ${ }^{2}$ The neuropathic pain associated with postherpetic neuralgia is persistent, severe and substantially interferes both with quality of life and recreational and daily activities. ${ }^{1,2}$ It even can induce the change from independent living to requiring dependent care. ${ }^{1}$ Unfortunately, there is not a single treatment that is completely effective or disease modifying for PHN. ${ }^{3}$ Considering that less than half of patients report greater than $50 \%$ pain relief with first-line medical therapy, existing medical treatment of postherpetic neuralgia is often refractory to multiple interventions. ${ }^{1,4}$

We present a case of a 71-year-old gentleman with postherpetic neuralgia initially in the left upper thoracic dermatomes, but with most severe pain along the distribution of the left intercostobrachial nerve (ICBN), which was refractory to initial treatment attempts. The patient ultimately responded to diagnostic local block followed by cryoneurolysis targeted along the ICBN anatomically. Despite multiple failed prior treatment attempts, the patient demonstrated sustained analgesia subsequent to the cryoneurolysis of the ICBN. To the authors' knowledge, this is the first reported case of refractory PHN that presented as ICBN neuralgia, which was successfully treated with cryoneurolysis/cryoanalgesia therapy.

\section{Case Report}

Department of Anesthesiology, New York Medical College, Westchester Medical Center, 100 Woods Road, Macy Room 239I, Valhalla, NY 10595, USA

Email garret.weber@wmchealth.org
Full informed written consent for the procedure and publication of this case report was obtained from the patient. No further institutional approvals were required. A 71-yearold gentleman with a past medical history of coronary artery disease, hyperlipidemia, 
anxiety and depression presented to the pain clinic with the chief complaint of persistent left back, flank and excruciating left arm pain. The pain started, approximately, 5 months prior to initial presentation, when he was diagnosed with acute herpes zoster in the same distribution (upper thoracic, approximately T2-5 dermatomes on left). The pain was severely limited to the patient's quality of life and ability to participate in activities of daily living (ADL).

The patient further described his pain as constant, severe, burning, pins and needles sensation. Average pain severity was reported as $>8 / 10$ (on NRS scale $0-10$ ) and significantly interfered with ADLs by impeding exercise, chores, self-care, socializing and sexual relations. The patient's history and the physical exam revealed his pain and allodynia were mainly located in the left upper arm along the anatomic ICBN distribution.

Initially, the patient's herpes zoster infection was treated with a course of valacyclovir, with the resolution of his rash. However, the pain persisted subsequently in a similar distribution. Initial treatments included (sequentially) gabapentin, pregabalin, lidocaine patch, amitriptyline and oxycodone. Despite multiple pharmacologic agents, he had limited-to-no relief and found the side effects including drowsiness and cognitive changes to be prohibitive. Epidural steroid injections were also attempted, but yielded minimal and no sustaining pain relief. The patient had attempted trigger point injections, intercostal nerve blocks (ICB), as well as stellate ganglion blocks. He had significant relief from the ICB; however, the pain seemed mainly focused and isolated in severity along the ICBN and there was no sustained analgesia when the local anesthetic had worn off. Given the reproducibility of the majority of his pain along the specific region of the ICBN, the decision was made to specifically target the ICBN for neural blockade and neurolysis. Following two successful diagnostic blocks ( $>50 \%$ pain reduction for the duration of local anesthetic) of the ICBN with local anesthesia only, it was agreed upon with the patient to pursue cryoneurolysis for greater sustained pain relief.

Informed procedural consent was obtained from the patient. In the supine position, the patient's arm was abducted and externally rotated. The area was prepped with a chlorhexidine solution and a 25-gauge needle was used to deposit local anesthetic solution just distal to the axillary fossa, from the deltoid muscle toward the triceps muscle along the anatomic localization of the ICBN (Figure 1). Ten milliliters of a solution containing $5 \mathrm{ml} 0.25 \%$ bupivacaine, $4 \mathrm{ml}$ of $1 \%$ lidocaine and $10 \mathrm{mg}$ of triamcinolone was injected. After adequate anesthesia was obtained, cryoneurolysis was performed using a

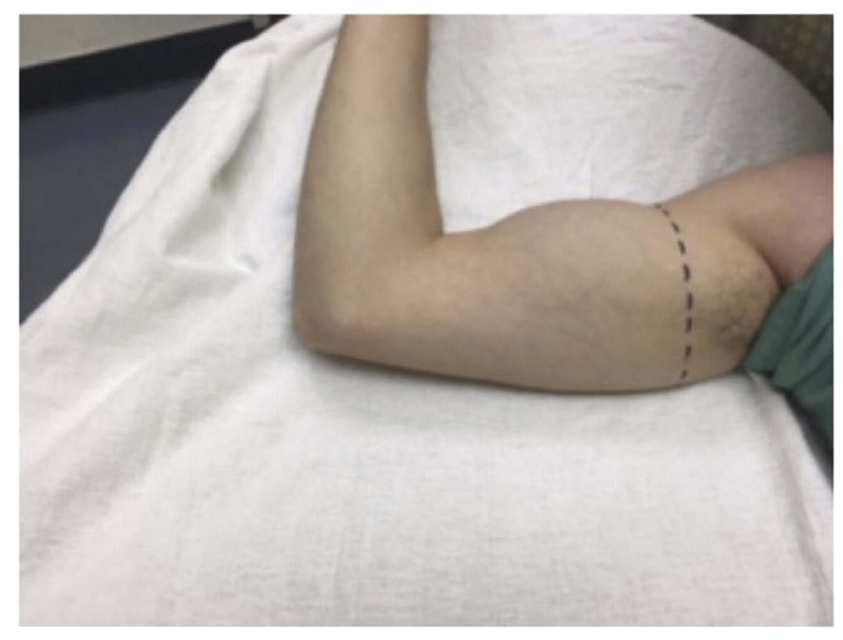

Figure I Approximate site of injection for local block and treatment line for cryoablation of intercostobrachial nerve (dotted line).

Note: This image is not the actual patient in the case report.

handheld cryoneurolysis device (Iovera). ${ }^{5}$ A 3 probe cryoablation tip probe (with three $27 \mathrm{~g}$ needles, approximately $7.6 \mathrm{~mm}$ in length) was used along the aforementioned treatment line. The tip of the cryoneurolysis probe was placed along the distribution of the ICBN. The device was used on the dotted line shown in Figure 1, moving circumferentially to cover the entire cross-section of the ICBN. The superficial nature of the field block allowed for the use of the cryoablation needles used in this case as described in Figure 2 to cover the length and depth of the intercostobrachial nerve. Nerve stimulation was not used to identify the exact localization as this nerve is generally located via a field block along anatomical landmarks only.

Multiple cycles of cryotherapy lasting $60 \mathrm{~s}$ in the treatment line as described above were administered with three $27-\mathrm{g}$ needles at a depth of approximately $5.1 \mathrm{~mm}$. The tip of the three-prong needle (Figure 2) achieved a cooling temperature of maximum -88 degree Celsius. The patient tolerated the procedure well, without any complications reported. At onemonth postprocedure, the patient reported greater than $50 \%$ pain relief (NRS $<4$ on the NRS scale) in the ICBN distribution with significant improvement in self-reported quality of life and activity. The patient did not require any further interventions and reported that the quality of life indicators mentioned earlier were no longer significantly debilitating his lifestyle. He did not need any further follow-up due to improved analgesia.

\section{Discussion}

Herpes zoster is a viral disease caused by reactivation of latent varicella zoster virus (VZV), characterized by a 


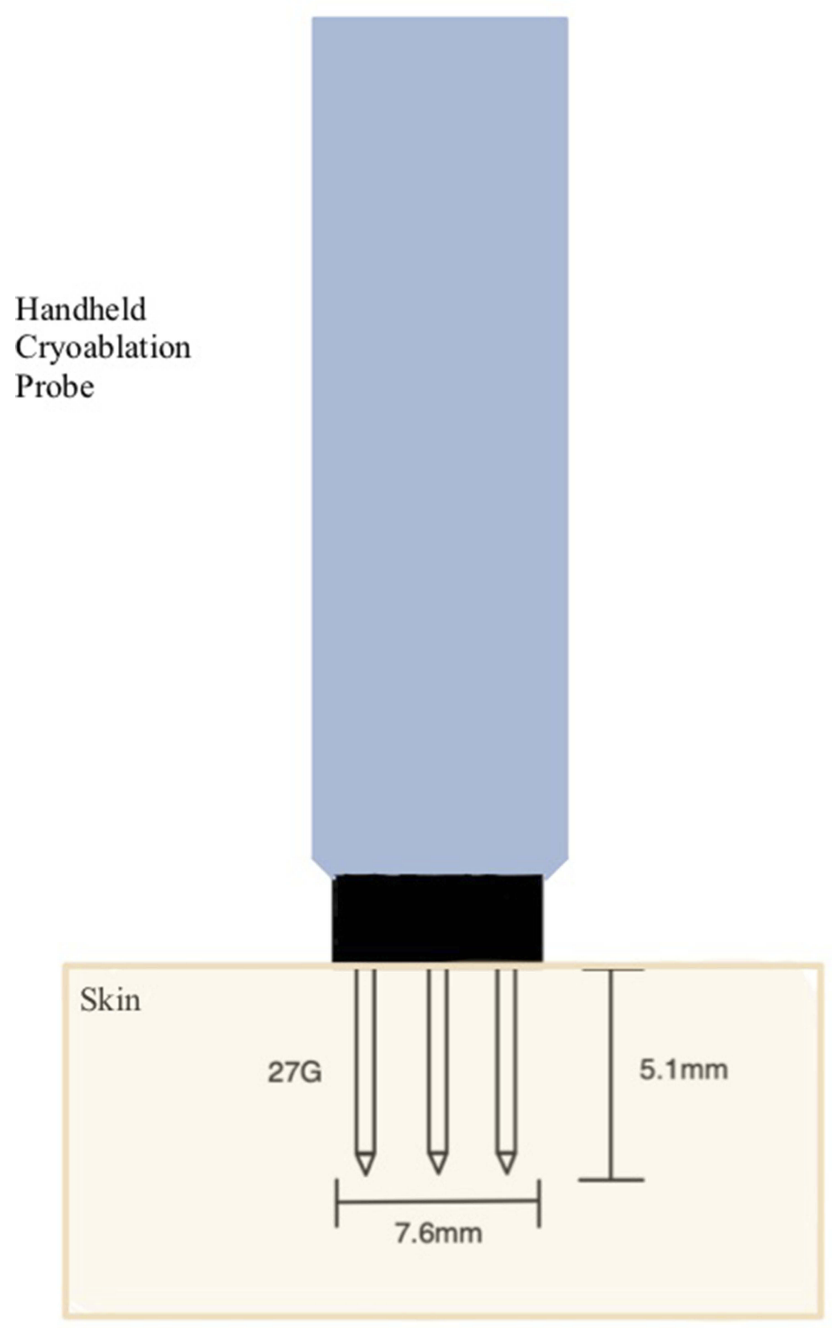

Figure 2 A 3-pronged cryoablation device (with three 27-g needles, approximately $7.6 \mathrm{~mm}$ in length) was used along the treatment line shown in Figure I, moving circumferentially to cover the entire cross-section of the ICBN. Multiple cycles of cryotherapy lasting $60 \mathrm{~s}$ in the treatment line as described above were administered with three $27-\mathrm{g}$ needles at a depth of approximately $5.1 \mathrm{~mm}$. The tips of the threeprong needle achieved a cooling temperature of maximum -88 degree Celsius.

vesicular rash distributing in a dermatomal pattern. The incidence of this disease in the United States is estimated to be 3.4 per 1000 persons, increasing significantly after age 50 to 11 per 1000 persons by age $90 .^{1}$ Approximately $10-20 \%$ of these cases in older individuals will develop $\mathrm{PHN}^{2} \mathrm{PHN}$ is a neuropathic pain condition defined by severe pain often with allodynia in a dermatomal pattern persisting for months after VZV occurrence and resolution. ${ }^{2,3}$ The pain often precludes functioning, preventing sleep, recreation and can be associated with depression. ${ }^{2}$ While the reactivation in acute herpes zoster virus is thought to propagate from the dorsal root ganglion, it is thought that chronic pain with PHN is related to an ongoing inflammatory response, which may also lead to injury of the peripheral nerve in addition to the DRG and higher order somatosensory processing ${ }^{6}$ The authors of this case report hypothesize that this may be the pathophysiologic basis for successful treatment of PHN with cryoablation of the intercostobrachial nerve in the patient presented. This theory has been supported by multiple reported effective peripheral nerve treatments for painful PHN. ${ }^{7,8,15,18}$ Currently, the usual treatment is multimodal, often including a combination of different pharmacologic classes of medications in addition to topical agents. These include gabapentinoids, tricyclic antidepressants, and opioids. ${ }^{9}$ Unfortunately, treatment of PHN is often inadequate with less than half of patients reporting greater than $50 \%$ pain relief with first-line medical therapy. ${ }^{1,4}$ Furthermore, the adverse effects of the mentioned standard treatments are often additive which limit dose escalation and tolerability, especially in older patients. ${ }^{9,10}$

Cryoneurolysis/cryoablation/cryoanalgesia therapy has been well described for is a well-established treatment for chronic pain states including neuropathic pain ${ }^{11}$ Recently cryoanalgesic techniques have even been applied to acute and perioperative pain states. ${ }^{12,13}$ The concept behind cryoanalgesia/neurolysis involves inducing cold temperature in the proximity of a peripheral nerve by creating ice crystals that will cause reversible axonal degeneration also known as Wallerian degeneration. ${ }^{5,14}$ The mechanism of analgesia in cryoanalgesia is multifold. There may be reduction of conduction, activation of descending inhibitory modulation, decreased excitatory neurotransmission, generalized sodium channel blockage, and likely a combination of all of the above ${ }^{14}$ There are several advantages of cryoablative techniques over other neurolytic techniques including surgical, thermal and chemical ablation (eg, alcohol neurolysis). First, in cryoablation, the epineurium, perineurium and endoneurium are generally intact. ${ }^{12-14}$ This allows for nerve regeneration and reduced risk of neuroma as compared with other neurolytic modalities, which is especially common after surgical neural resection ${ }^{11}$ Neuroma formation can significantly worsen pre-existing pain. Additionally, cryoablation is much less invasive compared with other techniques. Although pulsed radiofrequency (PRF) ablation has recently been described in setting of PHN, there is a larger probe $22 \mathrm{~g}$ for PRF vs $27 \mathrm{~g}$ in our case, which can be more painful for patient ${ }^{15}$ Also in Makharita's series there was PRF of the intercostal nerves and not specifically the ICBN $^{15}$ (which will be discussed later). The adverse effects and contraindications 
to cryoneurolysis include bleeding, skin discoloration and infection. As expected, the treatment area will likely become insensate. In our case, these risks were deemed to be exceedingly minimal due to the superficial nature of the cryoablation and probe used. The contraindications to cryoablation, specifically, include patients who have a history cryoglobulinemia, Raynaud's syndrome or cold urticaria. $^{5}$ Our patient had none of these features. Recently a handheld, cryoprobe (Iovera, FDA approved) has been developed and used in a variety of acute and chronic pain states. ${ }^{5,12,13,16}$ The cryoablation probe produces a focused, extremely cold temperature at its tip via the Joule Thompson effect. The basic principle is when high-pressure gas in the device (nitrous oxide) passes to a low-pressure chamber, there is the production of extremely cold temperature. ${ }^{5}$ This allows for localized cryoablation that is minimally invasive and an in-office procedure.

While cryoablation has been described for PHN as well as intercostal neuralgia and post-thoracotomy pain, ${ }^{11,17,18}$ to our knowledge this is the first reported case to specifically target the ICBN as a neuralgia, directly related to PHN. The ICBN is often affected/injured postmastectomy and there is literature regarding postmastectomy altered sensitivity with intercostobrachial neuralgia. ${ }^{19}$ The ICBN is at significant risk for injury postoperatively after procedures involving the axillary region. ${ }^{20}$ The ICBN is a cutaneous nerve that stems from the second and occasionally third intercostal nerve anatomically. ${ }^{21}$ One case series by Wisotzky et al demonstrated significant pain relief in patients with ICBN neuralgia, post breast cancer surgery with ICBN blocks. ${ }^{22}$ However, there were no patients with PHN reported, and the series only looked at 3 patients who were injected with local anesthetic and steroid; no neurolysis was performed. ${ }^{22}$

Given the severity of PHN and disabling pain to patients with limited options, we believe that cryoablation offers an alternative that is minimally invasive, with less risk compared to other forms of neurolysis. Our case report demonstrates an ICBN neuralgia related to PHN, which to our knowledge has not been reported in the literature and treated with cryoablation. While we acknowledge that additional studies are necessary and the conflicting data on efficacy of cryoablation with intercostal blocks and with post-thoracotomy pain, ${ }^{17,23}$ there have been positive results for cryoanalgesia for PHN in the dermatologic literature with cutaneous use ${ }^{18}$ Additionally, the minimal risk to ICBN cryoablation given the superficial nature, as compared to intercostal blocks, whose risks include pneumothorax and vascular uptake/bleeding, allows for the
ICBN cryoanalgesia to be a viable option that should be further explored in patients who present with features of ICBN neuralgia related to PHN.

\section{Funding}

The authors have no sources of funding to declare for this manuscript.

\section{Disclosure}

The authors declare no conflicts of interest in this work.

\section{References}

1. Johnson RW, Rice AS. Clinical practice. Postherpetic neuralgia. $N$ Engl J Med. 2014;371(16):1526-1533. doi:10.1056/NEJMcp1403062

2. Sampathkumar P, Drage LA, Martin DP. Herpes zoster (shingles) and postherpetic neuralgia. Mayo Clin Proc. 2009;84(3):274-280. doi: $10.4065 / 84.3 .274$

3. Schmader K. Herpes zoster. Clin Geriatr Med. 2016;32(3):539-553. doi:10.1016/j.cger.2016.02.011

4. Cohen JI. Clinical practice: herpes zoster. N Engl J Med. 2013;369 (3):255-263. doi:10.1056/NEJMcp 1302674

5. Ilfeld BM, Preciado J, Trescot AM. Novel cryoneurolysis device for the treatment of sensory and motor peripheral nerves. Expert Rev Med Devices. 2016;13(8):713-725. doi:10.1080/17434440.2016.1204229

6. Hadley GR, Gayle JR, Ripoll J, et al. Post-herpetic neuralgia: a review. Curr Pain Headache Rep. 2016;20(3):17. doi:10.1007/s119 16-016-0548-X

7. Ni J, Wang X, Tang Y, Zeng Y, Guo Y. Subcutaneous injection of triamcinolone and lidocaine to prevent postherpetic neuralgia. Pain Physician. 2017;20(5):397-403.

8. Lin C, Lin Y, Lao H, Chen C. Interventional treatments for postherpetic neuralgia: a systematic review. Pain Physician. 2019;22(3):209-228.

9. Whitley RJ. A 70-year-old woman with shingles: review of herpes zoster. JAMA. 2009;302(1):73-80. doi:10.1001/jama.2009.822

10. Pickering G, Leplege A. Herpes zoster pain, postherpetic neuralgia, and quality of life in the elderly. Pain Pract. 2011;11(4):397-402. doi:10.1111/j.1533-2500.2010.00432.x

11. Trescot AM. Cryoanalgesia in interventional pain management. Pain Physician. 2003;6(3):345-360.

12. Gabriel RA, Finneran JJ, Asokan D, Trescot AM, Sandhu NS, Ilfeld BM. Ultrasound-guided percutaneous cryoneurolysis for acute pain management: a case report. A A Case Rep. 2017;9(5):129-132. doi:10.1213/XA A. 0000000000000546

13. Gabriel RA, Finneran JJ 4th, Trescot AM, Ilfeld BM. Ultrasoundguided percutaneous cryoneurolysis for postoperative analgesia after limb amputation: a case series. A A Pract. 2019;12(7):231-234. doi:10.1213/XAA.0000000000000893

14. Bittman RW, Peters GL, Newsome JM, et al. Percutaneous imageguided cryoneurolysis. AJR Am J Roentgenol. 2018;210(2):454-465. doi:10.2214/AJR.17.18452

15. Makharita MY, El Bendary HM, Sonbul ZM, Ahmed SES, Latif MA. Ultrasound-guided pulsed radiofrequency in the management of thoracic postherpetic neuralgia: a randomized, double-blinded, controlled trial. Clin J Pain. 2018;34(11):1017-1024. doi:10.1097/AJP.000000 0000000629

16. Ilfeld BM, Gabriel RA, Trescot AM. Ultrasound-guided percutaneous cryoneurolysis providing postoperative analgesia lasting many weeks following a single administration: a replacement for continuous peripheral nerve blocks?: a case report. Korean J Anesthesiol. 2017;70 (5):567-570. doi:10.4097/kjae.2017.70.5.567 
17. Jones MJ, Murrin KR. Intercostal block with cryotherapy. Ann R Coll Surg Engl. 1987;69(6):261-262.

18. Calandria L. Cryoanalgesia for post-herpetic neuralgia: a new treatment. Int J Dermatol. 2011;50(6):746-750. doi:10.1111/j.1365-4632. 2010.04792.x

19. Couceiro TC, Menezes TC, Valênça MM. Post-mastectomy pain syndrome: the magnitude of the problem. Rev Bras Anestesiol. 2009;59(3):358-365. doi:10.1590/S0034-70942009000300012

20. Henry BM, Graves MJ, Pękala JR, et al. Origin, branching, and communications of the intercostobrachial nerve: a meta-analysis with implications for mastectomy and axillary lymph node dissection in breast cancer. Cureus. 2017;9(3):e1101.
21. Warrier S, Hwang S, Koh CE, et al. Preservation or division of the intercostobrachial nerve in axillary dissection for breast cancer: metaanalysis of randomised controlled trials. Breast. 2014;23(4):310-316. doi:10.1016/j.breast.2014.01.014

22. Wisotzky EM, Saini V, Kao C. Ultrasound-guided intercostobrachial nerve block for intercostobrachial neuralgia in breast cancer patients: a case series. Pm R. 2016;8(3):273-277. doi:10.1016/j.pmrj.2015.10.003

23. Khanbhai M, Yap KH, Mohamed S, Dunning J. Is cryoanalgesia effective for post-thoracotomy pain? Interact Cardiovasc Thorac Surg. 2014;18(2):202-209. doi:10.1093/icvts/ivt468

\section{Publish your work in this journal}

Local and Regional Anesthesia is an international, peer-reviewed, open access journal publishing on the development, pharmacology, delivery and targeting and clinical use of local and regional anesthetics and analgesics. The journal welcomes submitted papers covering original research, basic science, clinical studies, reviews \& evaluations, guidelines, expert opinion and commentary, case reports and extended reports. The manuscript management system is completely online and includes a very quick and fair peer-review system, which is all easy to use. Visit http://www.dovepress.com/testimonials. php to read real quotes from published authors. 